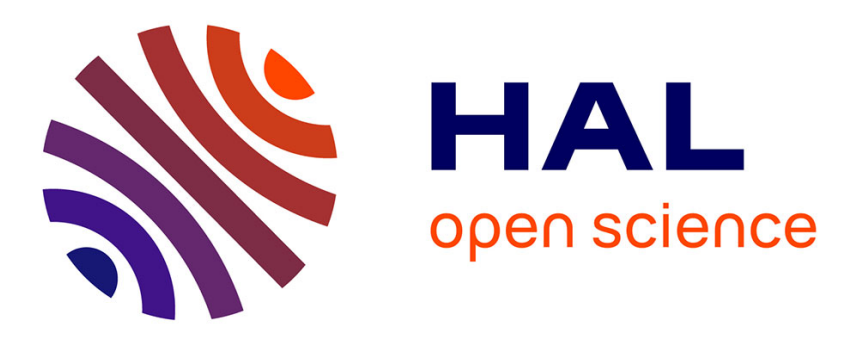

\title{
A new antimony-based organic-inorganic hybrid material as electron extraction layer for efficient and stable polymer solar cells
}

Donia Fredj, Riva Alkarsifi, Florent Pourcin, Xianjie Liu, Nassira Chniba

Boudjada, Pascal Pierron, Ali Nourdine, Mohamed Boujelbene, Mats

Fahlman, Christine Videlot-Ackermann, et al.

\section{To cite this version:}

Donia Fredj, Riva Alkarsifi, Florent Pourcin, Xianjie Liu, Nassira Chniba Boudjada, et al.. A new antimony-based organic-inorganic hybrid material as electron extraction layer for efficient and stable polymer solar cells. ACS Applied Materials \& Interfaces, 2019, 11 (47), pp.44820-44828. 10.1021/acsami.9b12409 . hal-02361212

\section{HAL Id: hal-02361212 \\ https://hal.science/hal-02361212}

Submitted on 10 Dec 2019

HAL is a multi-disciplinary open access archive for the deposit and dissemination of scientific research documents, whether they are published or not. The documents may come from teaching and research institutions in France or abroad, or from public or private research centers.
L'archive ouverte pluridisciplinaire HAL, est destinée au dépôt et à la diffusion de documents scientifiques de niveau recherche, publiés ou non, émanant des établissements d'enseignement et de recherche français ou étrangers, des laboratoires publics ou privés. 


\section{A new antimony-based organic-inorganic hybrid material as electron extraction layer for efficient and stable polymer solar cells}

Donia Fredj ${ }^{1,5}$, Riva Alkarsifi ${ }^{2}$, Florent Pourcin ${ }^{1}$, Xianjie Liu $^{3}$, Nassira Chniba Boudjada ${ }^{4}$, Pascal Pierron ${ }^{1}$, Ali Nourdine ${ }^{5}$, Mohamed Boujelbene ${ }^{6}$, Mats Fahlman ${ }^{3}$, Christine VidelotAckermann $^{2}$, Lionel Flandin ${ }^{5 *}$, Sadok Ben Dkhil ${ }^{1 *}$, Olivier Margeat ${ }^{2 *}$, Jörg Ackermann ${ }^{2}$

${ }^{1}$ Dracula Technologies, 4 Rue Georges Auric, 26000 Valence, France

${ }^{2}$ Aix Marseille Univ, CNRS, CINaM, Marseille, France.

${ }^{3}$ Laboratory for Organic Electronics, ITN, Linköping University, Norrköping, Sweden.

${ }^{4}$ Laboratoire de Cristallographie, CNRS, 25 Avenue des Martyrs, BP 166, 38042 Grenoble, France.

${ }^{5}$ Univ. Grenoble Alpes, Univ. Savoie Mont Blanc, CNRS, Grenoble INP (Institute of Engineering Univ. Grenoble Alpes), LEPMI, 38000 Grenoble, France

${ }^{6}$ Laboratoire Physico-Chimie de l'Etat Solide, LR11 ES51, Faculté des Sciences de Sfax, Université de Sfax, BP 3071 Sfax, Tunisie.

[*] Corresponding Authors:

E-mail address: s.bendkhil@dracula-technologies.com ; lionel.flandin@univ-smb.fr ; olivier.margeat@univ-amu.fr

\section{KEYWORDS:}

hybrid material; interfacial layer; nanocrystals; morphology; electron extraction; solar cell. 


\section{$\underline{\text { Abstract }}$}

Hybrid organic-inorganic materials are a new class of material used as interfacial layers in polymer solar cells. A hybrid material, composed of antimony as inorganic part and diaminopyridine as organic part, is synthesized and described as a new material for electron extraction layer in polymer solar cells and compared to the recently demonstrated hybrid materials using bismuth instead of antimony. The hybrid compound is solution-processed onto the photoactive layer based on a classical blend, composed of PTB7-Th low bandgap polymer as donor mixed with $\mathrm{PC}_{70} \mathrm{BM}$ fullerene as acceptor material. By using a regular device structure and an aluminum cathode, the solar cells exhibited a power conversion efficiency of $8.42 \%$, equivalent to the reference device using $\mathrm{ZnO}$ nanocrystals as interfacial layer, and strongly improved compared to bismuth-based hybrid material. The processing of extraction layers up to a thickness of $80 \mathrm{~nm}$ of such hybrid material reveals that the change from bismuth to antimony has strongly improved the charge extraction and transport properties of the hybrid materials. Interestingly, nanocomposites made of the hybrid material mixed with $\mathrm{ZnO}$ nanocrystals in a 1:1 ratio further improved the electronic properties of the extraction layers, leading to power conversion efficiency of $9.74 \%$. This was addressed to a more closely packed morphology of the hybrid layer, leading to further improved electron extraction. It is important to note that these hybrid electron extraction layers, both pure and ZnO-doped, also greatly improved the stability of solar cells, both under dark storage in air and under lighting under inert atmosphere compared to solar cells treated with $\mathrm{ZnO}$ intermediate layers.

\section{Introduction}

Polymer solar cells (PSCs) have recently experienced a renewal of interest thanks to power conversion efficiencies (PCEs) above $16 \%$ for both single and tandem configurations of heterojunction. ${ }^{1-3}$ The increase in performance is attributable to various improvements, i.e. on device structures, the use of better performing donor polymers, ${ }^{4-6}$ and mostly thanks to recent use of new non-fullerene (NF) acceptors. ${ }^{7-9}$ In fact, the quick development of NF PSCs during the past two years has benefited a lot from the synthetic methods, materials design strategies and device engineering protocols developed during the past two decades for fullerene-based 
PSCs. Even though the photoactive layer certainly governs the maximum efficiency of the solar cell, the interfacial layers (ILs) surrounding the photoactive layer are also of high importance as they are involved in efficient charge carrier extraction towards the electrodes minimizing the losses such as non-ohmic contact, charge carrier recombination and exciton quenching at the interfaces. ${ }^{10,11}$ Increasing the device performances of PSCs requires then deep studies concerning device architectures, processing techniques and the emergence of novel materials for both active layer and ILs. As for the interfacial materials, both regular and inverted device structures mostly use either pure organic ${ }^{12-16}$ or inorganic materials. ${ }^{17-22}$ Both material classes possess advantages and drawbacks. In the case of inorganic materials, metal oxides, such as $\mathrm{ZnO}$ or $\mathrm{TiO}_{\mathrm{x}}$, are ones of the mostly used materials as electron extraction layers (EELs) in both device structures, however it was shown that $\mathrm{ZnO}$ for instance leads to strong device degradation under AM1.5 illumination making UV-light filter necessary to improve the stability. ${ }^{23,24}$ Furthermore, metal oxides are known to introduce optical spacer effects in regular device structures that disturb the light distribution inside cells creating only narrow range of optimal thickness. ${ }^{25,26}$ For instance, in our previous studies, ${ }^{10,27}$ we were able to determine that $\mathrm{ZnO}$-based optical spacers provided high efficiencies only when the thickness of this layer was in the range of 20-25 nm, whereas photocurrent density losses (over $33 \%$ ) occurred when layers as thick as $75 \mathrm{~nm}$ were employed. In the case of organic interfacial layers, such as PEIE or PFN, very thin layers of few nanometers are often needed which makes their processing difficult and leads to stability issues. ${ }^{28}$ Hybrid organicinorganic materials are rather new material for and have been used as interfacial layers but mostly in form of nano-composites. ${ }^{29-31}$ Recently, we could demonstrate bismuth and diaminopyridine - based hybrid materials as new efficient EELs in PSCs using regular device structures. ${ }^{32}$ We demonstrated that this hybrid material $\left[\mathrm{C}_{5} \mathrm{H}_{8} \mathrm{~N}_{3}\right]_{2}\left[\mathrm{BiCl}_{5}\right]$ was highly suitable as EEL in organic solar cells as it can be processed as thick layers without reducing device performance due to optical spacer effect. Indeed, this hybrid material performed much better than $\mathrm{ZnO}$ processed with identical thickness of $80 \mathrm{~nm}$ thanks to only slight reduction in the photocurrent density, showing the robust layer processing of this type of material. However, we found that the transport properties of $\left[\mathrm{C}_{5} \mathrm{H}_{8} \mathrm{~N}_{3}\right]_{2}\left[\mathrm{BiCl}_{5}\right]$ were not optimal as the solar cells showed higher serial resistance compared to devices using $\mathrm{ZnO}$ as EEL.

Based on these results, we further enlarge this novel class of hybrid material by simply tuning the metal halogen counterpart of the hybrid material, in a similar approach to the composition tuning of the perovskite absorber materials, ${ }^{33}$ in order to find a material combination with 
lower electric resistance in EELs. In this objective, a new hybrid material based on antimony instead of bismuth in combination with diaminopyridine, namely $\left[\mathrm{C}_{5} \mathrm{H}_{8} \mathrm{~N}_{3}\right]_{2} \mathrm{SbCl}_{5}$ (noted HM), was developed that showed not only higher performance as EEL in polymer solar cells but also has improved transport properties compared to the former material. We show first the material synthesis followed by a detailed study of the physical properties both in solution and in thin films of $\left[\mathrm{C}_{5} \mathrm{H}_{8} \mathrm{~N}_{3}\right]_{2} \mathrm{SbCl}_{5}$ using $\mathrm{UV}-\mathrm{Vis}$ absorption spectroscopy, Fourier transform infrared and Raman spectroscopies, X-ray diffraction analysis, Atomic Force Microscopy and Ultraviolet Photoelectron Spectroscopy. Furthermore, solutions of well-dispersed HM nanocrystals in isopropanol were prepared in order to process EELs in PSCs, using regular device structure, in order to evaluate their optoelectronic properties. We used PTB7-Th as donor material in combination with $\mathrm{PC}_{70} \mathrm{BM}$ acceptor (chemical structures shown on Figure 1) and a regular device structure, ${ }^{27,34,35}$ in order to compare the HM materials to our recent work. $^{32}$ After optimizations, high efficient solar cells with power conversion efficiency of $8.42 \%$ could be obtained, demonstrating the high potential of this antimony-based hybrid material approach as IL. Importantly, in the case of $80 \mathrm{~nm}$ thick EELs, we found again only slight decrease in photocurrent density compared to thinner layers, indicating that optical spacer effects are less pronounced than in the case of $\mathrm{ZnO}$ based EELs. However, more importantly, the fill factors (FF) of the devices were generally strongly improved leading to FF of $65 \%$ even in the case of $80 \mathrm{~nm}$ thick HM layers. This demonstrates a clear improvement in the transport properties of HM, which is addressed to the use of antimony instead of bismuth in combination with diaminopyridine. As the nanoscale morphology of the EEL based on the HM materials still showed pinholes, we decided to process nanocomposite EEL based on $\mathrm{HM}$ mixed with $\mathrm{ZnO}$, in which $\mathrm{ZnO}$ is used to fill the pinholes. Interestingly, in the case of this HM-ZnO nanocomposite, solar cells with PCE as high as $9.74 \%$ could be obtained. This value is higher than the respective values of solar cells processed with either $\mathrm{HM}$ or $\mathrm{ZnO}$ separately, thanks to morphological improvements of the layer quality. We finally address also stability issues in the work and show that these novel antimony-based hybrid materials improve not only the air stability under dark storage, but also increase their stability under light illumination of the same cells, compared to devices using $\mathrm{ZnO}$. This is an important contribution to improve the overall stability of solar cells, especially for those devices using regular structure. 

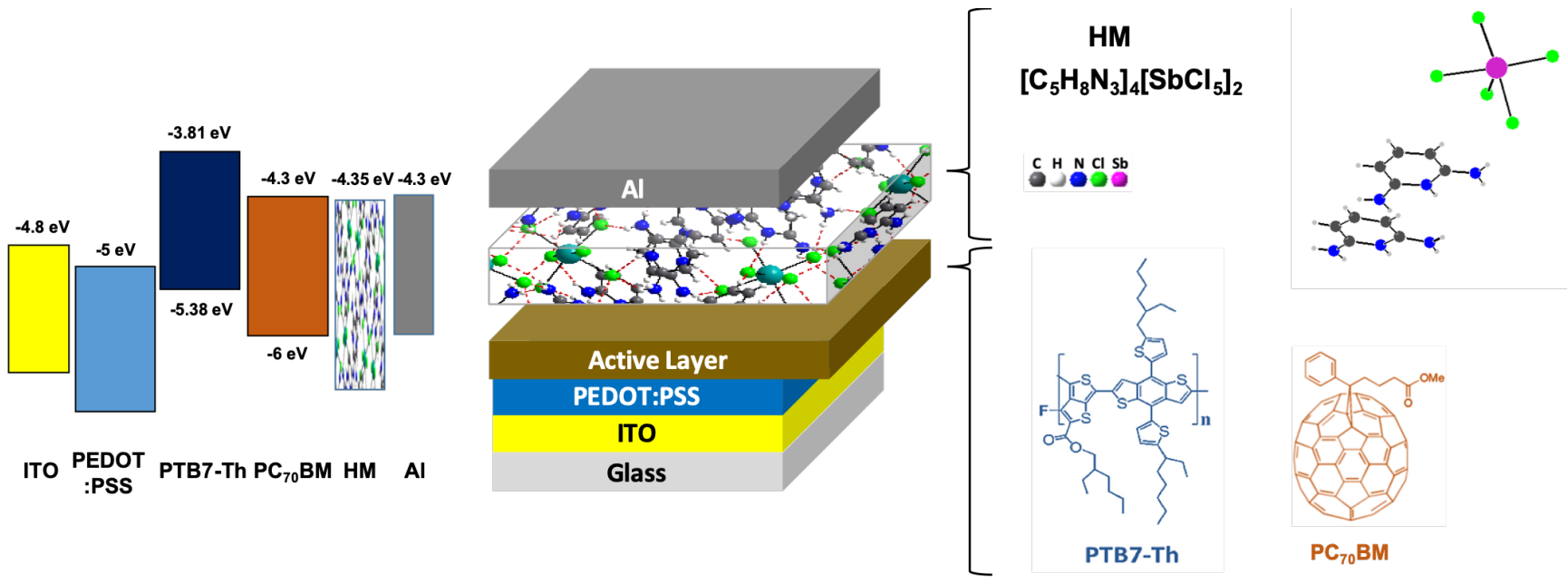

Figure 1. Schemes of the regular architecture (center) and the energy level diagram of the materials used (left). Molecular structures of donor (PTB7-Th), acceptor ( $\left.\mathrm{PC}_{70} \mathrm{BM}\right)$ materials and asymmetric unit of the hybrid material $\left[\mathrm{C}_{5} \mathrm{H}_{8} \mathrm{~N}_{3}\right]_{2} \mathrm{SbCl}_{5}$ (right).

\section{Experimental part}

\subsection{Materials}

For the synthesis of the hybrid material, 2,6 diaminopyridine $\left[\mathrm{C}_{5} \mathrm{H}_{7} \mathrm{~N}_{3}\right]$ (DAP) (purity 98\%) and antimony trichloride $\mathrm{SbCl}_{3}$ (purity 97\%) were obtained from Sigma-Aldrich and used without additional purification. PTB7-Th was purchased from 1-Materials. PEDOT: PSS (CLEVIOS AI 4083) was purchased from the Heraeus and the $\mathrm{PC}_{70} \mathrm{BM}$ as acceptor material, from Nano-C, (purity 99\%). The solvents additives 1,8-diodoctane (DIO), ethylene glycol (EG) and ethanolamine were also purchased from Sigma-Aldrich.

\subsection{Instruments and procedures}

Infrared Spectroscopy, UV-Vis measurements, Ultraviolet Photoelectron Spectroscopy and Thicknesses measurements were all realized using the same setups and procedures as described in our previous work. ${ }^{32}$

\section{${ }^{1}$ H Nuclear Magnetic Resonance (1H NMR)}

${ }^{1} \mathrm{H}$ NMR analyses were performed using a Bruker Advance III $400 \mathrm{MHz} /$ Ultrashield Plus Spectrometer System. The spectra were recorded at room temperature in DMSO as solvent at ambient temperature. Chemical shifts are expressed as $(\delta)$ and values are reported in parts per 
million (ppm) relative to tetramethylsilane (TMS) internal standard.

\section{Thermal Analysis}

The simultaneous thermogravimetric (TGA) and differential thermal analyses (DTA) were performed on a Setaram SETARAM TG-ATD instrument.

X-Ray analysis: Single crystal was selected for the diffraction experiments. The X-ray data collection was carried out on a Bruker APEXII CCD diffractometer using Mo/K $\alpha$ radiation $(\lambda=0.71073 \AA)$. The final cycle of refinement leads to the final discrepancy factors $\mathrm{R} 1=0.03$ and $\mathrm{wR} 2=0.13$. All crystallographic details and refinement parameters are summarized in Table S1 and the final atomic coordinates are reported in Table S2.

\section{Solar Cell Fabrication and Characterization}

Solar cells with regular device structure were processed on ITO substrates, covered by PEDOT:PSS, and measured as already described in previous work. ${ }^{36}$

\section{Results and discussion}

\subsection{Synthesis of hybrid materials}

The synthesis of the new antimony-based hybrid material $\left[\mathrm{C}_{5} \mathrm{H}_{8} \mathrm{~N}_{3}\right]_{2} \mathrm{SbCl}_{5}$ (HM) was performed according to the reaction shown in Equation 1 using as reagents 2,6 diaminopyridine (DAP) and antimony trichloride with molar ratio of 2:1. The aqueous solutions containing the two reagents were prepared by dispersion in deionized water under stirring during for 4 hours at room temperature. Then, the solutions were mixed and gradually acidified with concentrated hydrochloric acid to ensure the complete dissolution of the reactants. The reaction medium was stirred and kept at room temperature for 2 hours. Crystals of HM were obtained by slow evaporation after few weeks under ambient conditions and then characterized at solid state by IR, Raman and X-ray diffraction techniques and in solution by ${ }^{1} \mathrm{H}-\mathrm{NMR}$ spectroscopy.

$$
2 \mathrm{C}_{5} \mathrm{H}_{7} \mathrm{~N}_{3}+\mathrm{SbCl}_{3}+2 \mathrm{HCl} \stackrel{\mathrm{H}_{2} \mathrm{O}}{\longrightarrow}\left[\mathrm{C}_{5} \mathrm{H}_{8} \mathrm{~N}_{3}\right]_{2} \mathrm{SbCl}_{5}
$$

Equation 1. Synthetic scheme for the synthesis of the $\left[\mathrm{C}_{5} \mathrm{H}_{8} \mathrm{~N}_{3}\right]_{2} \mathrm{SbCl}_{5}$ complex 
In order to verify the complete complexation of $\mathrm{SbCl}_{3}$ with DAP, ${ }^{1} \mathrm{H}-\mathrm{NMR}$ analyses were performed on HM and DAP (Figure S1). The effect of coordination on the environment of the covalent bonds is confirmed and the chemical shift of characteristic protons are completely changed after complexation with apparition of a new proton signal at $12.67 \mathrm{ppm}$ resulting from the protonation of nitrogen of pyridine cycle in acidic conditions on the synthesis. In addition, the complete disappearance of DAP signals is evidenced which indicates the overall complexation between $\mathrm{SbCl}_{3}$ and DAP. Indeed, after complexation, the chemical shifts $\delta$ of protons detected in NMR appear at higher $\delta\left(5.28 \rightarrow 7.25\right.$ ppm for $-\mathrm{NH}_{2}$, $5.60 \rightarrow 5.87 \mathrm{ppm}$, aromatic protons in position 3 and 5 , and $7.00 \rightarrow 7.49 \mathrm{ppm}$ ).

The thermal behavior of the HM crystal was studied using the thermogravimetric analysis and the differential thermal analysis at a heating rate of $5{ }^{\circ} \mathrm{C} / \mathrm{min}$. The compound $\mathrm{HM}$ is stable up to $244^{\circ} \mathrm{C}$ as determined by TGA analyses (Figure S2a). Indeed, the TGA curve exhibited a whole weight starting at $244^{\circ} \mathrm{C}$ due to the continuous decomposition of the sample which is confirmed by DTA (Figure S2b). The other peak observed at $145^{\circ} \mathrm{C}$ can be assigned to the melting of the sample.

\subsection{Description of the structure}

The HM compound crystallizes in the monoclinic system ( $\mathrm{P} 2{ }_{1} / \mathrm{c}$ space group); with unit cell dimensions $\mathrm{a}=9.11$ (5), $\mathrm{b}=20.39(5)$ (5), $\mathrm{c}=10.32(5), \alpha=90, \beta=97.43$ (5) and $\gamma=90$. The crystal structure of the $\left[\mathrm{C}_{5} \mathrm{H}_{8} \mathrm{~N}_{3}\right]_{2} \mathrm{SbCl}_{5}$ is built of a pentachloroantimonate (III) anion and two mono-protonated cations $\left[\mathrm{C}_{5} \mathrm{H}_{8} \mathrm{~N}_{3}\right]^{+}$as shown in the asymmetric unit in Figure1. The structural arrangement of this compound can be described as organic layers alternate with inorganic layers stacked along $(b+c)$ and $(b-c)$ directions and which are isolated from each other to form (0D) network (Figure S3).

In contrast to hybrid material obtained by bismuth trichloride, ${ }^{32}$ inorganic entities are formed here by pentachloroantimonate(III) anions which exhibit square pyramid geometry. The $\mathrm{Sb}-\mathrm{Cl}$ distances are in the range $2.384(8)-2.681(14) \AA$ and angles Cl-Sb-Cl vary from $85.7(3)$ to $174.58(6)^{\circ}$ (Table S3a). These distances are clearly smaller than the sum of Van der Waals radii of $\mathrm{Sb}$ and $\mathrm{Cl}$ (4.0 $\AA$ according to Pauling), ${ }^{37,38}$ confirming the covalent character of the chlorine-antimony bond. More importantly, the distance between two atoms Sb01 is very large $(4.471 \AA)$, even larger than the double of the sum of van der Waals radii linking two 
antimony atoms. ${ }^{39}$ This high value may be due to the interference between the stereochemical activity of two opposites $\mathrm{Sb}(5 \mathrm{~s} 2)$ lone pair (E). In this structure, cations are formed by organic chains forming zig-zag lines rotating around the $\vec{b}$ axis (Figure $\mathbf{S 3 b}$ ), which are parallel to each other and separated by $\pi-\pi$ interactions with distances of $3.770(<3.8 \AA)$. The 2,6-diaminopyridinium cations involve distances C-C and C-N varying from 1.328(1) to 1.386(1) $\AA$, the C-C-C, C-N-C, N-C-C and N-C-N angles vary from 117.1(6) to $124.7(7)^{\circ}$ (Table S3b). Additionally, in the crystal structure, the $\left[\mathrm{C}_{5} \mathrm{H}_{8} \mathrm{~N}_{3}\right]^{+}$cations are linked to $\left[\mathrm{SbCl}_{5}\right]^{2-}$ by $\mathrm{N}-\mathrm{H}$....Cl hydrogen bonds with bond lengths varying from 3.273 to $3.665 \AA$ (Table S4).

\subsection{Vibrational study}

To get more insights about structure, we used vibrational study using Raman scattering and infrared absorption at room temperature. We thus assigned the observed bands by comparing them with previously vibrational studies reported on similar compounds. ${ }^{32,40}$ The IR and Raman spectra are presented in Figure 2, whereas the corresponding attributions proposed are illustrated in Table S5.

As shown in Figure 2, IR spectroscopy reveals the existence of covalent bonds in the organic part of complex before and after complexation. The spectra of organic ligand 2,6diaminopyridine (DAP) is given for comparison. As the functional groups of DAP and HM are based on similar chemical bonds, the chemical structure remains almost unchanged after complexation with only an additional bond of $\mathrm{N}^{+}-\mathrm{H}$ resulting from the protonation of the nitrogen on the pyridine cycle. However, the frequency shifts of characteristic peaks $\left(\delta_{\mathrm{N}-\mathrm{H}}\right.$ $1640 \rightarrow 1737 \mathrm{~cm}^{-1} ;$ varomatic $-\mathrm{C}-\mathrm{C}=\mathrm{N}-1583 \rightarrow 1633 \mathrm{~cm}^{-1}, v_{\text {aromatic } \mathrm{C}=\mathrm{C}} 1336 \rightarrow 1488 \mathrm{~cm}^{-1}, \delta_{\text {aromatic }}$ $=\mathrm{C}-\mathrm{H} \quad 795 \rightarrow 767 \mathrm{~cm}^{-1}$ ) indicate the change on the environment of the covalent bonds. This is attributed to the coordination bond between antimony and nitrogen. The bands observed between 3388 and $3256 \mathrm{~cm}^{-1}$ and at $2351 \mathrm{~cm}^{-1}$ in the infrared spectra can be attributed to stretching $\mathrm{NH}_{2}$ vibrations $v\left(\mathrm{NH}_{2}\right)$. The peaks appearing between 3193 and $2992 \mathrm{~cm}^{-1}$ are assigned to stretching vibration of $\mathrm{C}-\mathrm{H}$ which is in agreement with the values found in bismuth-based analogs. ${ }^{32}$ The peaks observed at 2099 and $1960 \mathrm{~cm}^{-1}$ in the infrared spectra can be attributed to the stretching mode of $\mathrm{N}-\mathrm{H} \ldots \mathrm{Cl} v(\mathrm{~N}-\mathrm{H} \ldots \mathrm{Cl})$.

Lower wave numbers in the Raman spectrum, shown in Figure 2c, allow detecting the characteristic peaks of both organic DAP ligand ( $\rho_{\mathrm{NH} 2}$ and $\delta_{\text {aromatic }=\mathrm{C}-\mathrm{H}}$ between 1061 and 999 $\mathrm{cm}^{-1}, \omega_{\mathrm{NH} 2}$ and $\beta_{\text {aromatic -CCC- }}$ at $759 \mathrm{~cm}^{-1}, \delta_{\text {aromatic -CCC- }}$ at $569 \mathrm{~cm}^{-1}, \beta_{\text {aromatic -CCN- and }} \delta_{\text {aromatic -CCC- }}$ 
at $538 \mathrm{~cm}^{-1}, \tau_{-\mathrm{NH} 2}$ and $\delta_{\text {aromatic -CCC- }}$ at 346 and $319 \mathrm{~cm}^{-1}$ ) and metallic part ( $\mathrm{Sb} v_{\mathrm{SbCl}}$ at $245 \mathrm{~cm}^{-}$ ${ }^{1}$ ) of the complex. This confirms the coordination bond between antimony and nitrogen.
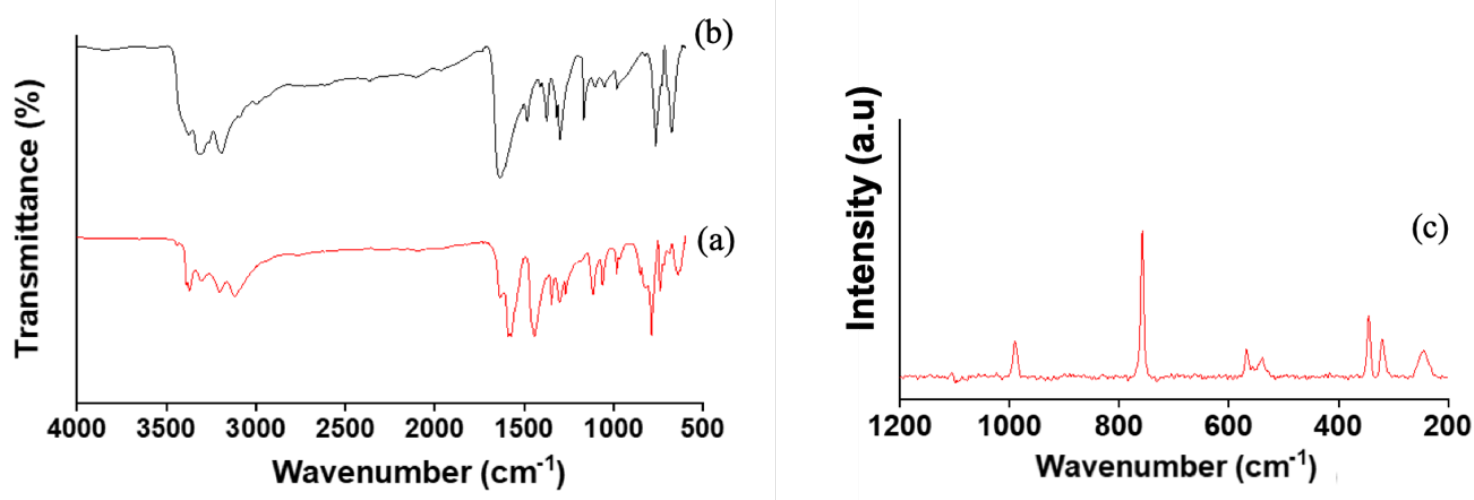

Figure 2. Infrared spectra of the organic part DAP (a) and the hybrid $\left[\mathrm{C}_{5} \mathrm{H}_{8} \mathrm{~N}_{3}\right]_{2} \mathrm{SbCl}_{5}$ (b). Raman spectrum of $\left[\mathrm{C}_{5} \mathrm{H}_{8} \mathrm{~N}_{3}\right]_{2} \mathrm{SbCl}_{5}(\mathrm{c})$.

\subsection{Thin films characterizations}

Characterizations of the hybrid material HM were evaluated in solution as well as in thin films produced on glass substrates. Identically to our recent work on hybrid materials, ${ }^{32}$ isopropanol was chosen as solvent to prepare solution of dispersed nanocrystals by intense sonication treatment of the large hybrid crystals. Ethylene glycol was used as additive to improve the dispersion quality leading to highly dispersed HM solutions. As shown in Figure 3a, AFM analyses reveal that the nearly close packed layers are obtained on glass with a root mean square roughness in the range of 2 to $4 \mathrm{~nm}$. Absorption spectra of both solution and thin films of the HM compound are presented in Figure 3b. It can be seen that the material exhibits an absorption band in solution and thin film centered at 336 and at $341 \mathrm{~nm}$, respectively. The values are similar to those observed in the case of the bismuth-based analogs as they are due to the antimony $5 \mathrm{~s}$ to $5 \mathrm{p}$ transition. ${ }^{41}$ The properties of the materials such as optical bandgap and energy levels are key parameters to apply this new hybrid material as IL in organic solar cells. From the absorption band cutoff on the absorption spectra of the thin film, we could estimate the optical band gap at $3.37 \mathrm{eV}$ for this new hybrid material. We can thus estimate the conduction band edge energy versus vacuum level by determining the energy of the valence band edge (ionization potential, IP) from the ultraviolet photoelectron spectroscopy spectra (UPS) and the onset of the optical absorption. Figure S4 shows the UPS data of the HM, from which we determined WF and IP values of $4.29 \mathrm{eV}$ and $7.29 \mathrm{eV}$ respectively, yielding in a conduction band edge of $4.0 \mathrm{eV}$. The WF of $\mathrm{HM}$ is at a 
sufficiently low value to form suitable contact with the fullerene acceptors, and not with the donor polymers. These analyses show clearly that these novel hybrid materials are well suitable as EEL in polymer solar cells.

a)

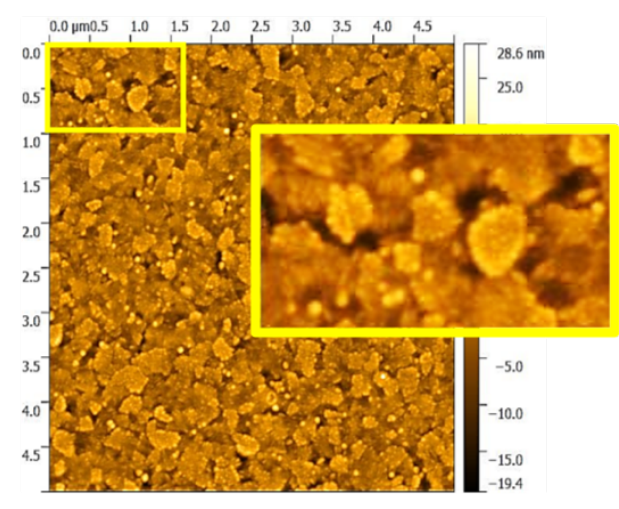

b)

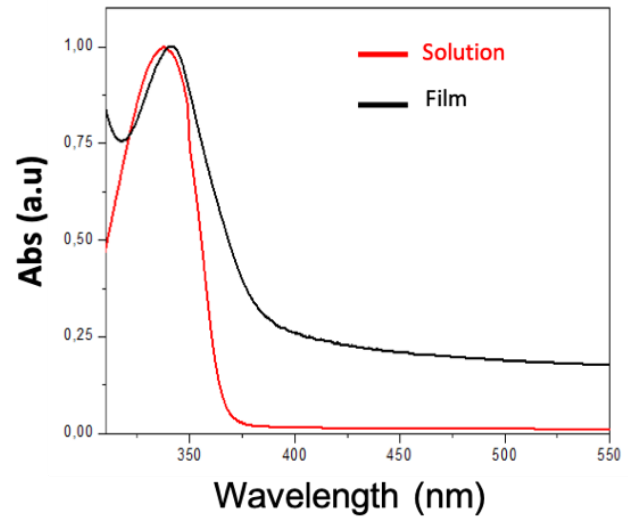

c)

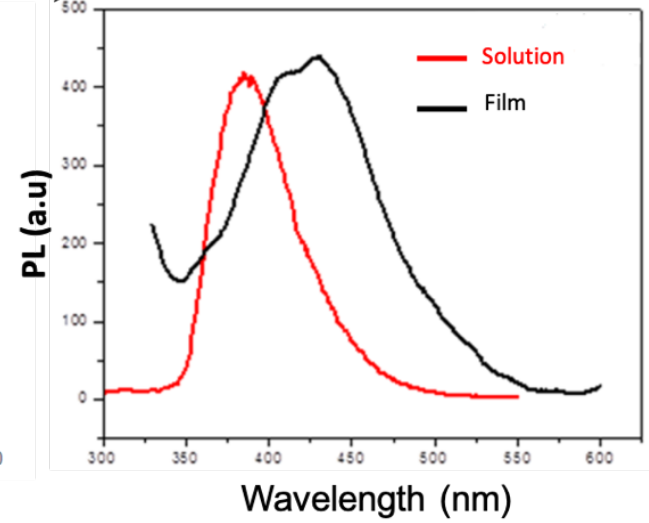

Figure 3. AFM image of the layer obtained with the hybrid material HM (a). UV-Vis absorption spectra (b) and photoluminescence (c) measured for both solution and thin films.

\subsection{Polymer solar cells using HM as EEL}

\subsubsection{Performances of HM materials}

In order to evaluate the potential of the new antimony-based hybrid material HM for polymer solar cells, we performed HM nanocrystal-based layer on top of the photoactive one, building a device structure ITO/PEDOT:PSS/PTB7-Th:PC $70 \mathrm{BM} / \mathrm{EEL} / \mathrm{Al}$. We performed classical optimization steps such as variation of EEL thickness and annealing temperature of the deposited layers. Figure 4 and Figure S5 show the $J-V$ curves of the different optimization steps, while Table 1 summarizes the corresponding photovoltaic parameters along with statistics from ten cells. 


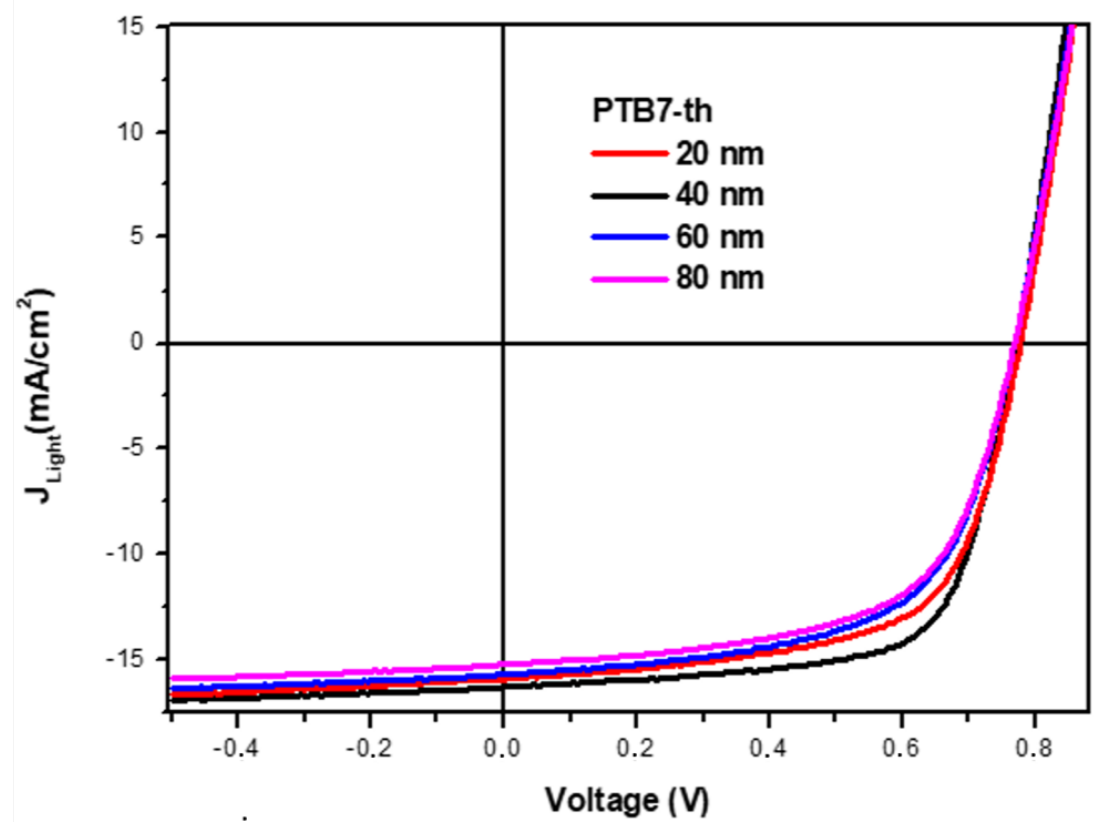

Figure 4. J(V) curves of ITO/PEDOT:PSS/PTB7-Th:PC $70 \mathrm{BM} / \mathrm{HM} / \mathrm{Al}$ devices structures for various HM thicknesses.

\begin{tabular}{|c|c|c|c|c|c|}
\hline Thickness of the EEL layer (nm) & PCE (\%) & VoC $(\mathbf{m V})$ & $\mathbf{J}_{\text {SC }}\left(\mathbf{m A} / \mathbf{c m}^{2}\right)$ & FF (\%) & $\begin{array}{c}\text { Average PCE ( } \\
\text { std.dev) }\end{array}$ \\
\hline $\mathbf{2 0}$ & 8.14 & 776 & 15.91 & 66 & $8.016 \pm 0.09$ \\
\hline $\mathbf{4 0}$ & 8.42 & 771 & 16.31 & 67 & $8.19 \pm 0.14$ \\
\hline $\mathbf{6 0}$ & 8.06 & 768 & 15.67 & 67 & $7.93 \pm 0.10$ \\
\hline $\mathbf{8 0}$ & 7.59 & 768 & 15.21 & 65 & $7.34 \pm 0.17$ \\
\hline
\end{tabular}

Table 1. Photovoltaic parameters (PCE, $\mathrm{V}_{\mathrm{OC}}, \mathrm{J}_{\mathrm{SC}}$ and FF) of ITO/PEDOT:PSS/PTB7$\mathrm{Th}: \mathrm{PC}_{70} \mathrm{BM} / \mathrm{HM} / \mathrm{Al}$ devices structures for various $\mathrm{HM}$ thicknesses.

The highest PCE was obtained with an EEL film thickness of $40 \mathrm{~nm}$ using an annealing temperature of $80^{\circ} \mathrm{C}$. For all thicknesses, the low values of the standard deviations in PCE 
indicate the high layer quality and is a factor to ensure good reproducibility of solar cells performance. In our previous work, ${ }^{32}$ we have demonstrated a hybrid high band gap material composed of bismuth and diaminopyridine which gave efficient electron extraction layers in polymer solar cells leading to PCEs exceeding 7.8 \% using PTB7-Th: PC $_{70} \mathrm{BM}$ based active layer in regular device structure. The novel HM material presented in this work thus improves the performance of the solar cells up to $8.42 \%$ and particularly increases the FF from $62 \%$ to $67 \%$. Regarding the impact of the EEL thickness variation on the device performance, we find that the photocurrent is almost constant for all devices, which is similar to our observation of device using bismuth-based hybrid materials as interfacial layers. ${ }^{32}$ Thus, both hybrid materials show an effect that is in stark contrast to ZnO-based EELs as ZnO EELs lead under identical conditions to stronger loss in photocurrent density up to $33 \%$ due to negative optical spacer effect in the regular device structure. ${ }^{10,27}$ Regarding the impact of EEL thickness variation on the FF of the devices, there are also negligible losses when increasing the thickness from $40 \mathrm{~nm}$ to $80 \mathrm{~nm}$, as the FF decreased only from $67 \%$ to $65 \%$.This is a strong improvement compared to the former hybrid materials based on bismuth. In order to better understand the improvement of FF and thus PCE when processed with such novel EELs, we determined the serial resistance $R_{\mathrm{S}}$ as a function of interfacial layer by fitting the corresponding $\mathrm{J}(\mathrm{V})$ curves (see Table S7). A comparison is also made with $\mathrm{ZnO}$ and the hybrid materials based on bismuth previously published. ${ }^{32}$ The values of the series resistance in the case of the present antimony-based HM are found lower than the ones obtained in the case of the bismuth analog as well as with ZnO-based EELs. The serial resistance of the bismuth material was typically $8.1 \Omega \mathrm{cm}^{2}$ at $40 \mathrm{~nm}$ thickness and increased to $9.9 \Omega \mathrm{cm}^{2}$ for EEL of $80 \mathrm{~nm}$ thickness, ${ }^{32}$ indicating the charge transport and electron extraction of the hybrid material are not optimal. In the case of $\mathrm{ZnO}$ based EELs, $R_{\mathrm{S}}$ was found at $4.7 \Omega \mathrm{cm}^{2}$ for $40 \mathrm{~nm}$ thick EEL, that increases only slightly to $5.1 \Omega \mathrm{cm}^{2}$ for $80 \mathrm{~nm}$ thick layer, indicating that both extraction barrier and charge transport are better compared to the bismuth-based hybrid material. Looking at the new antimony-based hybrid material, the serial resistance is $3.7 \Omega \mathrm{cm}^{2}$ for $40 \mathrm{~nm}$ thick EELs and increases only slightly to $4.4 \Omega \mathrm{cm}^{2}$ in the case of $80 \mathrm{~nm}$ thick EELs (see Table S8). It has to be noted that all materials, i.e. HM, the bismuth-based analog hybrid materials, as well as the $\mathrm{ZnO}$ nanoparticles, were all processed from IPA solution on top of the photoactive layers, using identical device structure and photoactive materials. We can thus conclude that the improvements in performance of the solar cells using HM as EEL is directly related to its electronic properties and not to changes of the photoactive nanoscale morphology due to solvent effects. 
These results demonstrate thus that change from bismuth to antimony produces a novel hybrid EEL material with improved extraction barrier and charge transport. Taking into account that solar cells using $80 \mathrm{~nm}$ thick EELs based on this novel material show only $10 \%$ losses in power conversion efficiency compared to devices using thin EEL layers, this novel material can be considered as a very promising candidate towards thick layer robust processing of organic solar cells.

\subsubsection{Processing and performances of $\mathrm{HM}-\mathrm{ZnO}$ composite materials}

We have shown that optimized cells using HM present high FF accompanied by a high $\mathrm{J}_{\mathrm{SC}}$ of $16.31 \mathrm{~mA} / \mathrm{cm}^{2}$, close to the values obtained with interfacial layers based on $\mathrm{ZnO}$ nanoparticles. ${ }^{32,42}$ However, there are still limitations of the HM compared to $\mathrm{ZnO}$. In the case of open-circuit voltage, the value of the $\mathrm{V}_{\mathrm{OC}}$, which is $771 \mathrm{mV}$, remains lower than the ones obtained with $\mathrm{ZnO}(800 \mathrm{mV})$, which can be addressed to not optimized energy fitting between the LUMO level of the fullerenes and the work function of HM. Furthermore, the fill factor of the solar cells processed with HM as EEL reaches values up to $67 \%$, while solar cells processed with ZnO-based EELs show values of $69 \%$, although the serial resistance of the device using HM are even slightly lower than those observed in solar cells using $\mathrm{ZnO}$ as EEL. One possibility for the lower FF could have its origin in the layer morphology of the HMbased EELs which is not optimal. Indeed, the nanoscale morphology of interfacial layers has a strong impact on FF in normal device structures. ${ }^{10}$ As show before, HM layers have high surface roughness with few pinholes and have thus poor layer quality compared to ZnO-based EELs.

In order to improve further the interfacial properties of the HM, we produce a composite made of $\mathrm{ZnO}$ nanoparticles with the HM. The idea behind the composite approach is that the addition of $\mathrm{ZnO}$ nanoparticles into the HM material may allow processing of closely packed hybrid layer with more suitable energy levels and thus higher $\mathrm{V}_{\mathrm{OC}}$. Both $\mathrm{ZnO}$ nanoparticles and the HM nanocrystals are soluble in the same solvent and require the same additive to obtain good dispersion. In order to prepare the composite ink, a solution of the compound HM was prepared under the same conditions as previously described, using isopropanol and ethylene glycol as solvent and additive. Then, $\mathrm{ZnO}$ nanoparticles were added resulting in a very homogeneous solution using a 1:1 vol. ratio of $\mathrm{HM}(25 \mathrm{mg} / \mathrm{mL}): \mathrm{ZnO}(5 \mathrm{mg} / \mathrm{mL})$. The nanoscale morphology of the $\mathrm{HM}-\mathrm{ZnO}$ layers obtained from this new composite solution have 
been first studied by AFM. The results shown in Figure 5 reveal that the composite layers are closely packed with the formation of a uniform network of $\mathrm{HM}$ crystals in a $\mathrm{ZnO}$ matrix. $\mathrm{ZnO}$ nanoparticles appear to envelop HM nanocrystals on one side and fill the holes in the layer on the other side. Theses morphological improvements are expected to improve solar cell performances as it has already been demonstrated recently that optimal $\mathrm{ZnO}$-based layers need to be closely-packed and hole free in order to obtain high FF. ${ }^{10,43}$

(a)
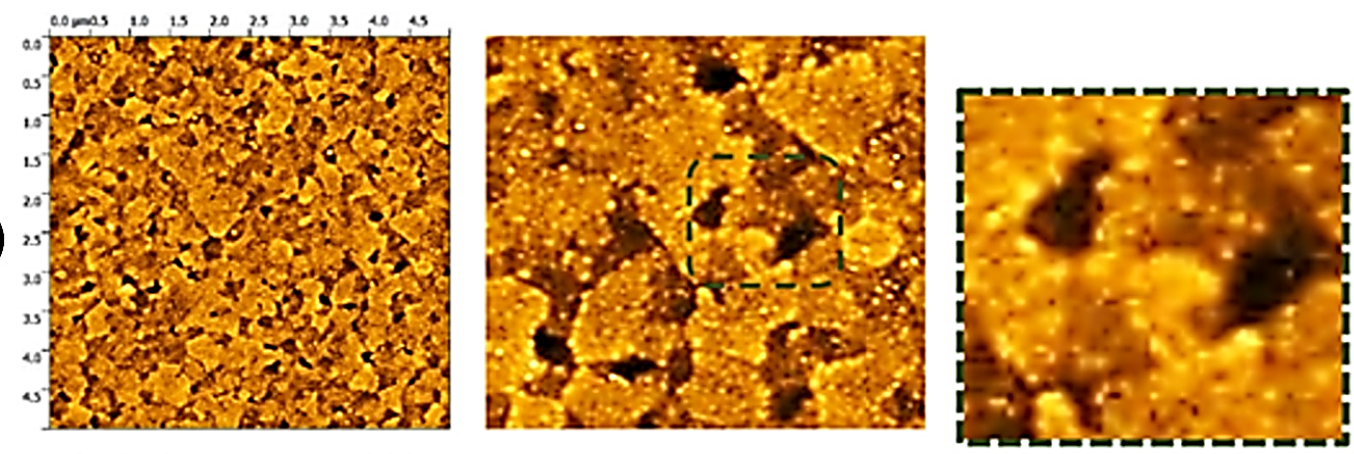

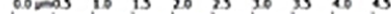
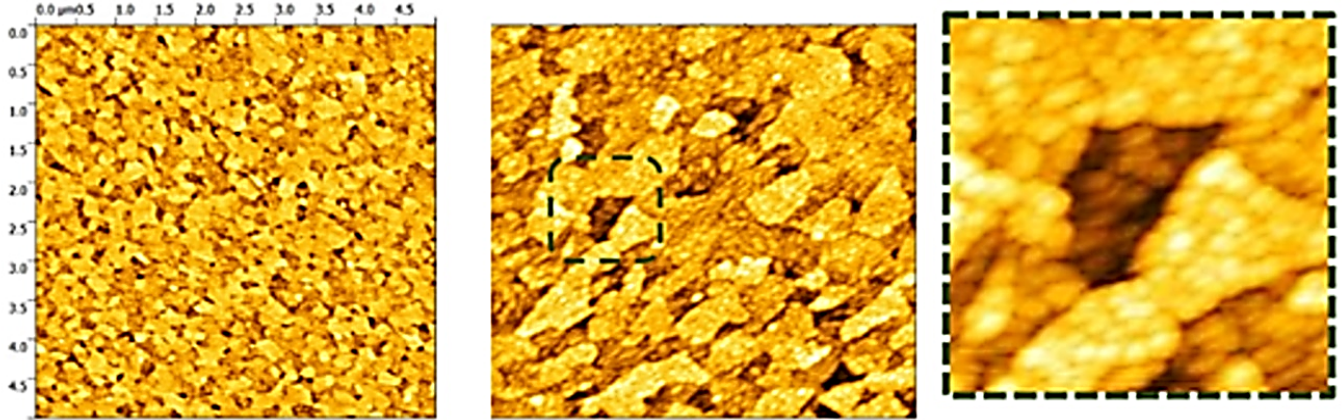

Figure 5. AFM images of the pure HM layer (a) and the HM- $\mathrm{ZnO}$ composite layer (b).

Figure 6 compares the J(V) curves of polymer solar cells processed with either $\mathrm{ZnO}$ or the composite $\mathrm{HM}-\mathrm{ZnO}$ as EEL. The solar cells using the HM-ZnO interfacial layers show clearly improved $\mathrm{J}(\mathrm{V})$ curves resulting in PCE of $9.74 \%$ due to strongly improved photovoltaic parameters compared to layer using HM only. Indeed, these devices show very high fill factor FF of $73 \%$ that can be addressed to a synergistic effect of improved layer quality and electronic properties of the hybrid material. The series resistance of the HM-ZnO based cells drops to $1.6 \Omega \mathrm{cm}^{2}$ (Table S7), indicating that electron extraction was strongly improved using this composite material compared to $\mathrm{HM}$ and $\mathrm{ZnO}$. The better charge extraction goes in line with the $\mathrm{J}_{\mathrm{SC}}$, which is also significantly increased, reaching high values up to $17.03 \mathrm{~mA} \cdot \mathrm{cm}^{-2}$. External quantum efficiency measurements (EQE) were performed to demonstrate the impact of the three different $\mathrm{ZnO}, \mathrm{HM}$ or $\mathrm{HM}-\mathrm{ZnO}$ interfacial layers on this photocurrent generation. Figure S7 shows the measured EQE spectra for the three types of 
cells and it is clear that the EQE spectrum obtained with the HM-ZnO interfacial layer has the highest response in the spectral range of 350 to $750 \mathrm{~nm}$. A maximum EQE of $82 \%$ measured at $477 \mathrm{~nm}$ correlates well with the increase of photocurrent observed in the case of HM-ZnO compared to the spectrum with pure $\mathrm{ZnO}$. The new $\mathrm{HM}-\mathrm{ZnO}$ interfacial layer has also improved the value of the $\mathrm{V}_{O C}$. This new value of the $\mathrm{V}_{O C}$ is intermediate between that of the $\mathrm{ZnO}$ and that of the $\mathrm{HM}$ materials, which can be addressed to an intermediate work function of the composite material, as the mixing ratio of $\mathrm{ZnO}$ and $\mathrm{HM}$ is $1: 1$. In conclusion, the combination of $\mathrm{HM}$ and $\mathrm{ZnO}$ into a novel composite materials allows to circumvent the remaining limitation of the novel antimony-based hybrid material and to even outperform $\mathrm{ZnO}$ as interfacial material in polymer solar cells using normal device structures.

\begin{tabular}{|c|r|r|r|r|}
\hline EEL & PCE (\%) & $\mathbf{V}_{\text {OC }}(\mathbf{m V})$ & $\mathbf{J}_{\text {SC }}\left(\mathbf{m A} / \mathbf{c m}^{2}\right)$ & FF (\%) \\
\hline ZnO & 9.18 & 800 & 16.39 & 70 \\
\hline HM-ZnO & 9.74 & 784 & 17.03 & 73 \\
\hline
\end{tabular}

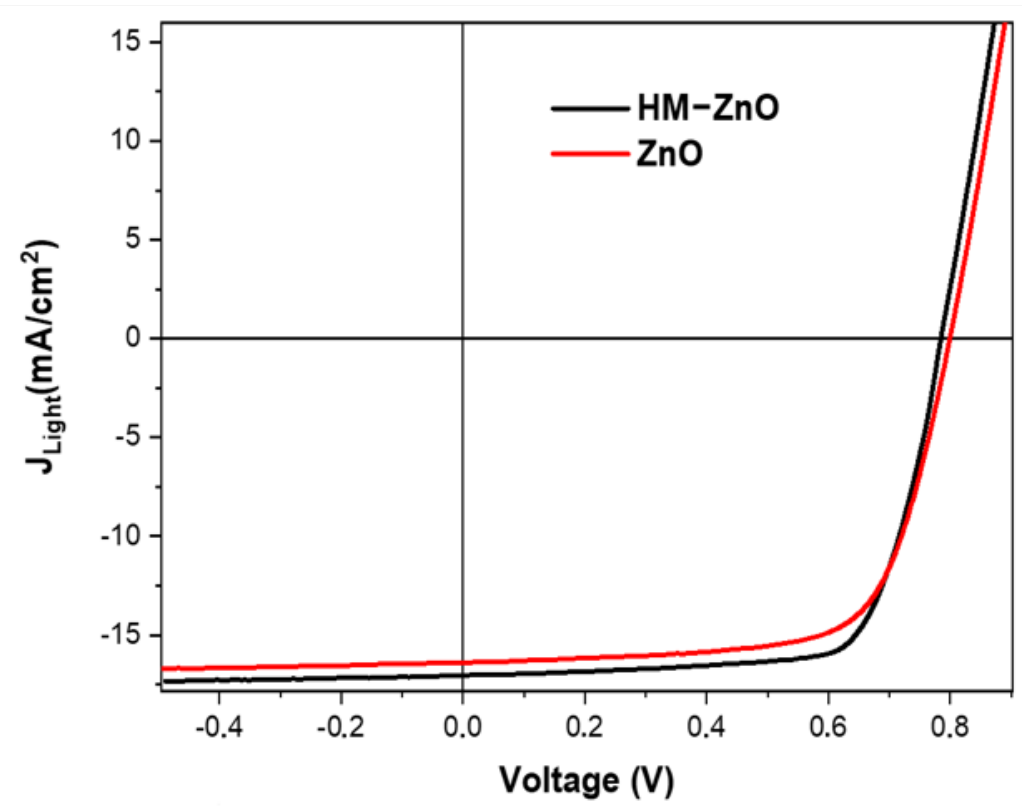

Figure 6. J(V) curves of ITO/PEDOT:PSS/PTB7-Th:PC $70 \mathrm{BM} / \mathrm{EEL} / \mathrm{Al}$ devices structures for the $\mathrm{ZnO}$ and $\mathrm{HM}-\mathrm{ZnO}$ materials (bottom) and reported photovoltaic performances (top).

\subsubsection{Stability studies}


Together with efficiency and cost, the stability is one of the crucial factors to validate Polymer Solar Cells technologies. ${ }^{44,45}$ And the stability of PSCs is still a major issue, which needs to be solved for an effective industrial exploitation. Here, we discuss the impact of the hybrid materials $\mathrm{HM}$ and $\mathrm{HM}-\mathrm{ZnO}$ on the stability of the complete organic devices in air and under continuous illumination, compared to devices processed with ZnO-based EELs.

In the case of the bismuth-based hybrid materials, we demonstrated already a higher air storage stability of solar cells using theses hybrid interfacial layers compared to interlayer based on classical $\mathrm{ZnO} .^{32}$ Therefore, we first evaluate the air storage stability of the new antimony-based hybrid interfacial materials to see whether there is a general tendency of these hybrid interfacial layers to be more stable in air than metal oxide materials such as $\mathrm{ZnO}$. The $\mathrm{J}-\mathrm{V}$ curves of the three type of solar cells were measured over the period of one week under dark storage in air using open circuit conditions. The evolution of the J-V curves of the solar cells using the two hybrid materials types are presented on Figure 7, while Table S9 shows the time evolution of the related photovoltaic parameters. In the case of devices based on $\mathrm{ZnO}$ EEL, we already demonstrated in our previous work that a continuous degradation over time was found with only $20 \%$ of the initial PCE value preserved after 7 days. ${ }^{32}$ The major losses in this case were related to the formation of an S-shape visible in the $\mathrm{J}-\mathrm{V}$ curves. The formation of such an S-shape in polymer solar cells using ZnO EELs in regular device structures has already been explained. ${ }^{46}$ A chemical reaction at the interface between $\mathrm{ZnO}$ and the aluminum electrode was met even under inert atmosphere, that generates the formation of an aluminum oxide layer between $\mathrm{ZnO}$ and the $\mathrm{Al}$ cathode. In our stability tests, which are performed in air, such a chemical reaction at the $\mathrm{ZnO}-\mathrm{Al}$ interface is accelerated due to the presence of water and oxygen, which explains the fast formation of the S-shape in solar cell. ${ }^{32}$

Taking into account such a high reactivity of the interface between the aluminum electrode and the EEL layer, it is interesting to note that solar cells using the new antimony-based HM are much more stable under air storage over time. Indeed, solar cells based on HM EEL could preserve more than $80 \%$ of their initial PCE value up to seven days of exposure with no appearance of an S-shape. Compared to our former work on bismuth- based hybrid interfacial layers with $60 \%$ of the initial PCE value preserved after 7 days, ${ }^{32}$ the novel antimony-based hybrid interfacial material has thus improved the stability of the solar cells. Regarding the stability of solar cells using the composite HM-ZnO as EEL, our results reveal an improved device stability in air compared to devices using pure ZnO-based EEL. However, the stability was not as good as solar cells using pure HM as EEL, as these solar cells based on the HM- 
$\mathrm{ZnO}$ composite interlayer could maintain $70 \%$ of their initial PCE value up to 7 days of exposure.
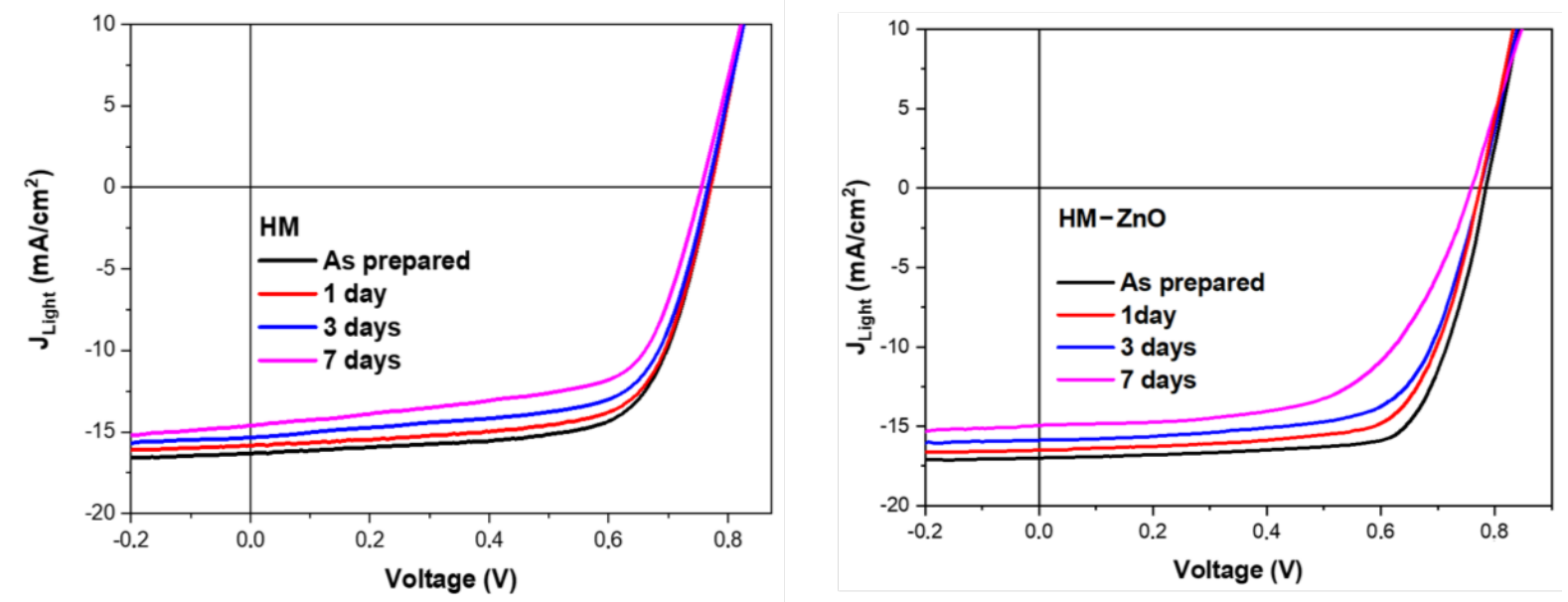

Figure 7. J(V) curves of ITO/PEDOT:PSS/PTB7-Th:PC ${ }_{70} \mathrm{BM} / \mathrm{EEL} / \mathrm{Al}$ devices as a function of storage time for $\mathrm{HM}$ (left) and $\mathrm{HM}-\mathrm{ZnO}$ (right) interfacial layers.

Furthermore, we studied the stability of the solar cells under continuous illumination under a simulated AM1.5 spectrum in inert atmosphere as the effect of oxygen and moisture under illumination accelerates the degradation of the organic devices. ${ }^{47}$ The solar cells were placed under continuous AM $1.5 \mathrm{G}$ illumination of $100 \mathrm{~mW} / \mathrm{cm}^{2}$ and the performances were measured for 15 days. The evolution of the J-V curves of different devices using the three different interfacial layers ( $\mathrm{ZnO}, \mathrm{HM}$ or $\mathrm{HM}-\mathrm{ZnO})$ are presented on Figure 8, while Table S10 gives the time evolution of the corresponding photovoltaic parameters. In the case of ZnO-based EEL, a degradation over time appears with only $30 \%$ of the initial PCE value remaining after 15 days. The $\mathrm{ZnO}$-based devices show losses in all photovoltaic parameters. In contrast, the devices based on the HM EEL retain more than $80 \%$ of its initial PCE, which is significantly higher than $\mathrm{ZnO}$-based devices. This result indicates that the replacement of $\mathrm{ZnO}$ layer by the antimony-based hybrid layer improved not only storage stability in air but also the photostability of complete devices. In the case of the cells based on the HM-ZnO composite EEL, the solar cells showed higher stability than devices using pure $\mathrm{ZnO}$, but slightly lower than those processed with the pure HM material. Indeed, the solar cells based on $\mathrm{HM}-\mathrm{ZnO}$ interlayer could maintain $70 \%$ of their initial PCE value up to 15 days of exposure. Our results clearly show two important findings. Firstly, the main origin of the degradation under air storage or continuous light soaking of the presented polymer solar cells 
which uses a regular device structure, are caused by the presence of $\mathrm{ZnO}$ as EEL and not, as generally believed in literature, related to the use of PEDOT:PSS. Indeed, all studied devices use PEDOT:PSS as HTL, but only devices using ZnO-based EELs degradate very fast in both conditions. Secondly, our novel hybrid materials, especially HM, allow reducing the degradation of polymer solar cells using regular device structures under air storage and illumination, respectively, confirming the high potential of these hybrid materials as new class of EEL materials for polymer solar cells. ${ }^{32}$
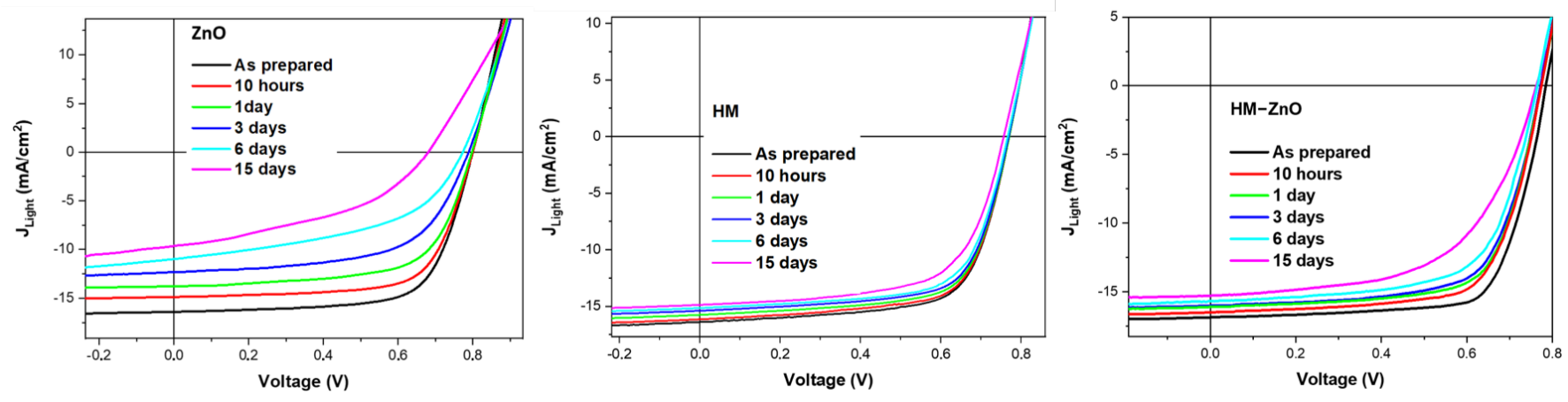

Figure 8. J(V) curves of ITO/PEDOT:PSS/PTB7-Th:PC $70 \mathrm{BM} / \mathrm{EEL} / \mathrm{Al}$ devices as a function of illumination time for $\mathrm{ZnO}$ (left), $\mathrm{HM}$ (center) and $\mathrm{HM}-\mathrm{ZnO}$ (right) interfacial layers.

\section{Conclusion}

A new organic-inorganic hybrid high band gap material composed of antimony and diaminopyridine has been synthesized and characterized as highly suitable for electron extraction layers in polymer solar cells leading to PCEs as high as $8.42 \%$ using PTB7$\mathrm{Th}: \mathrm{PC}_{70} \mathrm{BM}$ based active layer in regular device structure. Compared to the recently demonstrated hybrid materials using bismuth, this novel hybrid compound strongly improved the charge extraction and transport properties of the electron extraction layer. Producing a nanocomposite made of the hybrid materials mixed with $\mathrm{ZnO}$ nanocrystals even further improved the electronic properties of the extraction layers, leading to power conversion efficiency of $9.74 \%$. This enhancement was attributed to the fact that the nanocomposite improved the morphology of the hybrid interfacial layer. Importantly, when compared to solar cells using pristine $\mathrm{ZnO}$, the hybrid electron extraction layers (both pure or $\mathrm{ZnO}$-based nanocomposite) greatly improved the stability of the solar cells. This highlights the significant interest of this novel family of hybrid materials for applications in polymer solar energy 
conversion using normal device structures. Future work will study the potential of these hybrid materials as electron extraction layers in polymer solar cells using an inverted device structure.

Supporting Information. Crystallographic data for $\left[\mathrm{C}_{5} \mathrm{H}_{8} \mathrm{~N}_{3}\right]_{2} \mathrm{SbCl}_{5} .{ }^{1} \mathrm{H}-\mathrm{NMR}$ spectra. TGA and DTA scans. Assignments of IR and Raman wavenumbers. UPS spectra of HM films. J(V) curves of ITO/PEDOT:PSS/PTB7-Th:PC $70 \mathrm{BM} / \mathrm{HM} / \mathrm{Al}$ devices structures for various $\mathrm{HM}$ annealing temperatures. AFM images of the active layer. EQE analysis. Photovoltaic parameters of ITO/PEDOT:PSS/PTB7-Th:PC $70 \mathrm{BM} / \mathrm{EEL} / \mathrm{Al}$ devices as a function of storage time and illumination time.

\section{Author Contributions}

The manuscript was written through contributions of all authors. All authors have given approval to the final version of the manuscript.

\section{Acknowledgements}

The authors thank A. Ranguis for AFM measurements, I. Ozerov \& F. Bedu for profilometer measurements performed at PLANETE CT PACA cleanroom facility (CINaM, Marseille). They also acknowledge LEPMI laboratory to make available measurements performed at INES Chambéry. MF and XL acknowledge support from the Swedish Research Council project grant 2016-05498 and the Swedish Government Strategic Research Area in Materials Science on Functional Materials at Linköping University (Faculty Grant SFO Mat LiU No 2009 00971).

\section{References}

(1) Li, H.; Xiao, Z.; Ding, L.; Wang, J. Thermostable Single-Junction Organic Solar Cells with a Power Conversion Efficiency of 14.62\%. Sci. Bull. 2018, 63 (6), 340-342. 
(2) Che, X.; Li, Y.; Qu, Y.; Forrest, S. R. High Fabrication Yield Organic Tandem Photovoltaics Combining Vacuum- and Solution-Processed Subcells with 15\% Efficiency. Nat. Energy 2018, 3 (5), 422-427.

(3) Fan, B.; Zhang, D.; Li, M.; Zhong, W.; Zeng, Z.; Ying, L.; Huang, F.; Cao, Y. Achieving over 16\% Efficiency for Single-Junction Organic Solar Cells. Sci. China Chem. 2019, 62 (6), 746-752.

(4) Scharber, M. C.; Mühlbacher, D.; Koppe, M.; Denk, P.; Waldauf, C.; Heeger, A. J.; Brabec, C. J. Design Rules for Donors in Bulk-Heterojunction Solar Cells - Towards 10 \% Energy-Conversion Efficiency. Adv. Mater. 2006, 18 (6), 789-794.

(5) Liu, C.; Wang, K.; Gong, X.; Heeger, A. J. Low Bandgap Semiconducting Polymers for Polymeric Photovoltaics. Chem. Soc. Rev. 2016, 45 (17), 4825-4846.

(6) Choi, H.; Ko, S.-J.; Kim, T.; Morin, P.-O.; Walker, B.; Lee, B. H.; Leclerc, M.; Kim, J. Y.; Heeger, A. J. Small-Bandgap Polymer Solar Cells with Unprecedented ShortCircuit Current Density and High Fill Factor. Adv. Mater. 2015, 27 (21), 3318-3324.

(7) Zhao, W.; Li, S.; Yao, H.; Zhang, S.; Zhang, Y.; Yang, B.; Hou, J. Molecular Optimization Enables over 13\% Efficiency in Organic Solar Cells. J. Am. Chem. Soc. 2017, 139 (21), 7148-7151.

(8) Holliday, S.; Ashraf, R. S.; Wadsworth, A.; Baran, D.; Yousaf, S. A.; Nielsen, C. B.; Tan, C.-H.; Dimitrov, S. D.; Shang, Z.; Gasparini, N.; et al. High-Efficiency and AirStable P3HT-Based Polymer Solar Cells with a New Non-Fullerene Acceptor. Nat. Commun. 2016, 7 (1), 11585.

(9) Li, S.; Ye, L.; Zhao, W.; Zhang, S.; Mukherjee, S.; Ade, H.; Hou, J. Energy-Level Modulation of Small-Molecule Electron Acceptors to Achieve over 12\% Efficiency in Polymer Solar Cells. Adv. Mater. 2016, 28 (42), 9423-9429.

(10) Dkhil, S. Ben; Duché, D.; Gaceur, M.; Thakur, A. K.; Aboura, F. B.; Escoubas, L.; Simon, J.-J.; Guerrero, A.; Bisquert, J.; Garcia-Belmonte, G.; et al. Interplay of Optical, Morphological, and Electronic Effects of ZnO Optical Spacers in Highly Efficient Polymer Solar Cells. Adv. Energy Mater. 2014, 4 (18), 1400805.

(11) Po, R.; Carbonera, C.; Bernardi, A.; Camaioni, N. The Role of Buffer Layers in Polymer Solar Cells. Energy Environ. Sci. 2011, 4 (2), 285-310. 
(12) He, Z.; Wu, H.; Cao, Y. Recent Advances in Polymer Solar Cells: Realization of High Device Performance by Incorporating Water/Alcohol-Soluble Conjugated Polymers as Electrode Buffer Layer. Adv. Mater. 2014, 26 (7), 1006-1024.

(13) Li, Y.-L.; Cheng, Y.-S.; Yeh, P.-N.; Liao, S.-H.; Chen, S.-A. Structure Tuning of Crown Ether Grafted Conjugated Polymers as the Electron Transport Layer in BulkHeterojunction Polymer Solar Cells for High Performance. Adv. Funct. Mater. 2014, 24 (43), 6811-6817.

(14) Liu, S.; Zhang, K.; Lu, J.; Zhang, J.; Yip, H. L.; Huang, F.; Cao, Y. High-Efficiency Polymer Solar Cells via the Incorporation of an Amino-Functionalized Conjugated Metallopolymer as a Cathode Interlayer. J. Am. Chem. Soc. 2013, 135 (41), 1532615329.

(15) Wang, Z.; Zheng, N.; Zhang, W.; Yan, H.; Xie, Z.; Ma, Y.; Huang, F.; Cao, Y. SelfDoped, n-Type Perylene Diimide Derivatives as Electron Transporting Layers for High-Efficiency Polymer Solar Cells. Adv. Energy Mater. 2017, 7 (15), 1700232.

(16) Zhang, L.; Liu, C.; Lai, T.; Huang, H.; Peng, X.; Huang, F.; Cao, Y. A Water/AlcoholSoluble Conjugated Porphyrin Small Molecule as a Cathode Interfacial Layer for Efficient Organic Photovoltaics. J. Mater. Chem. A 2016, 4 (39), 15156-15161.

(17) Loser, S.; Valle, B.; Luck, K. A.; Song, C. K.; Ogien, G.; Hersam, M. C.; Singer, K. D.; Marks, T. J. High-Efficiency Inverted Polymer Photovoltaics via Spectrally Tuned Absorption Enhancement. Adv. Energy Mater. 2014, 4 (14), 1301938.

(18) Park, S. H.; Roy, A.; Beaupré, S.; Cho, S.; Coates, N.; Moon, J. S.; Moses, D.; Leclerc, M.; Lee, K.; Heeger, A. J. Bulk Heterojunction Solar Cells with Internal Quantum Efficiency Approaching 100\%. Nat. Photonics 2009, 3 (5), 297-302.

(19) Trost, S.; Behrendt, A.; Becker, T.; Polywka, A.; Görrn, P.; Riedl, T. Tin Oxide (SnO x ) as Universal "Light-Soaking" Free Electron Extraction Material for Organic Solar Cells. Adv. Energy Mater. 2015, 5 (17), 1500277.

(20) Dong, Q.; Li, J.; Shi, Y.; Chen, M.; Ono, L. K.; Zhou, K.; Zhang, C.; Qi, Y.; Zhou, Y.; Padture, N. P.; et al. Improved SnO 2 Electron Transport Layers Solution-Deposited at Near Room Temperature for Rigid or Flexible Perovskite Solar Cells with High Efficiencies. Adv. Energy Mater. 2019, 1900834, 1900834. 
(21) Tountas, M.; Topal, Y.; Polydorou, E.; Soultati, A.; Verykios, A.; Kaltzoglou, A.; Papadopoulos, T. A.; Auras, F.; Seintis, K.; Fakis, M.; et al. Low Work Function Lacunary Polyoxometalates as Electron Transport Interlayers for Inverted Polymer Solar Cells of Improved Efficiency and Stability. ACS Appl. Mater. Interfaces 2017, 9 (27), 22773-22787.

(22) Raïssi, M.; Leroy-Lhez, S.; Ratier, B. Enhanced Photocurrent and Stability of Organic Solar Cells Using Solution-Based TS-CuPc Interfacial Layer. Org. Electron. 2016, 37, $183-189$.

(23) Manor, A.; Katz, E. A.; Tromholt, T.; Krebs, F. C. Electrical and Photo-Induced Degradation of ZnO Layers in Organic Photovoltaics. Adv. Energy Mater. 2011, 1 (5), $836-843$.

(24) Chapel, A.; Dkhil, S. Ben; Therias, S.; Gardette, J.-L.; Hannani, D.; Poize, G.; Gaceur, M.; Shah, S. M.; Wong-Wah-Chung, P.; Videlot-Ackermann, C.; et al. Effect of ZnO Nanoparticles on the Photochemical and Electronic Stability of P3HT Used in Polymer Solar Cells. Sol. Energy Mater. Sol. Cells 2016, 155, 79-87.

(25) Gilot, J.; Barbu, I.; Wienk, M. M.; Janssen, R. a. J. The Use of ZnO as Optical Spacer in Polymer Solar Cells: Theoretical and Experimental Study. Appl. Phys. Lett. 2007, 91 (11), 113520.

(26) Kim, J. Y.; Kim, S. H.; Lee, H.-H.; Lee, K.; Ma, W.; Gong, X.; Heeger, A. J. New Architecture for High-Efficiency Polymer Photovoltaic Cells Using Solution-Based Titanium Oxide as an Optical Spacer. Adv. Mater. 2006, 18 (5), 572-576.

(27) Dkhil, S. Ben; Pfannmöller, M.; Bals, S.; Koganezawa, T.; Yoshimoto, N.; Hannani, D.; Gaceur, M.; Videlot-Ackermann, C.; Margeat, O.; Ackermann, J. SquareCentimeter-Sized High-Efficiency Polymer Solar Cells: How the Processing Atmosphere and Film Quality Influence Performance at Large Scale. Adv. Energy Mater. 2016, 6 (13), 1600290.

(28) Yin, Z.; Wei, J.; Zheng, Q. Interfacial Materials for Organic Solar Cells: Recent Advances and Perspectives. Adv. Sci. 2016, 3 (8), 1-37.

(29) Small, C. E.; Chen, S.; Subbiah, J.; Amb, C. M.; Tsang, S.-W.; Lai, T.-H.; Reynolds, J. R.; So, F. High-Efficiency Inverted Dithienogermole-Thienopyrrolodione-Based Polymer Solar Cells. Nat. Photonics 2012, 6 (2), 115-120. 
(30) Liao, S.-H.; Jhuo, H.-J.; Cheng, Y.-S.; Chen, S.-A. Fullerene Derivative-Doped Zinc Oxide Nanofilm as the Cathode of Inverted Polymer Solar Cells with Low-Bandgap Polymer (PTB7-Th) for High Performance. Adv. Mater. 2013, 25 (34), 4766-4771.

(31) Yin, Z.; Zheng, Q.; Chen, S.-C.; Li, J.; Cai, D.; Ma, Y.; Wei, J. Solution-Derived Poly(Ethylene Glycol)-TiO x Nanocomposite Film as a Universal Cathode Buffer Layer for Enhancing Efficiency and Stability of Polymer Solar Cells. Nano Res. 2015, $8(2), 456-468$.

(32) Fredj, D.; Pourcin, F.; Alkarsifi, R.; Kilinc, V.; Liu, X.; Ben Dkhil, S.; Boudjada, N. C.; Fahlman, M.; Videlot-Ackermann, C.; Margeat, O.; et al. Fabrication and Characterization of Hybrid Organic-Inorganic Electron Extraction Layers for Polymer Solar Cells toward Improved Processing Robustness and Air Stability. ACS Appl. Mater. Interfaces 2018, 10 (20), 17309-17317.

(33) Bai, S.; Yuan, Z.; Gao, F. Colloidal Metal Halide Perovskite Nanocrystals: Synthesis, Characterization, and Applications. J. Mater. Chem. C 2016, 4 (18), 3898-3904.

(34) He, Z.; Zhong, C.; Su, S.; Xu, M.; Wu, H.; Cao, Y. Enhanced Power-Conversion Efficiency in Polymer Solar Cells Using an Inverted Device Structure. Nat. Photonics 2012, 6 (9), 591-595.

(35) He, Z.; Xiao, B.; Liu, F.; Wu, H.; Yang, Y.; Xiao, S.; Wang, C.; Russell, T. P.; Cao, Y. Single-Junction Polymer Solar Cells with High Efficiency and Photovoltage. Nat. Photonics 2015, 9 (3), 174-179.

(36) Ben Dkhil, S.; Gaceur, M.; Diallo, A. K.; Didane, Y.; Liu, X.; Fahlman, M.; Margeat, O.; Ackermann, J.; Videlot-Ackermann, C. Reduction of Charge-Carrier Recombination at ZnO-Polymer Blend Interfaces in PTB7-Based Bulk Heterojunction Solar Cells Using Regular Device Structure: Impact of ZnO Nanoparticle Size and Surfactant. ACS Appl. Mater. Interfaces 2017, 9 (20), 17256-17264.

(37) Aloui, Z.; Ferretti, V.; Abid, S.; Rzaigui, M.; Lefebvre, F.; Ben Nasr, C. Synthesis, Crystal Structure and Characterization of a New Organic-Inorganic Hybrid Material: [C6H16N2O]SbCl5. J. Mol. Struct. 2015, 1087, 26-32.

(38) Pauling, L. The Nature of the Chemical Bond and the Structure of Molecules and Crystals : An Introduction to Modern Structural Chemistry; Cornell University Press, I., Ed.; 1960. 
(39) Galy, J.; Enjalbert, R. Crystal Chemistry of the VA Element Trihalides: Lone Pair, Stereochemistry, and Structural Relationships. J. Solid State Chem. 1982, 44 (1), 1-23.

(40) Fredj, D.; Hassen, C. Ben; Elleuch, S.; Feki, H.; Boudjada, N. C.; Mhiri, T.; Boujelbene, M. Structural, Vibrational and Optical Properties of a New OrganicInorganic Material: (C 5 H 8 N 3 ) 2 [BiCl 5 ]. Mater. Res. Bull. 2017, 85 (85), 23-29.

(41) Mason, W. R. Electronic Absorption and MCD Spectra for BiX 63 - , X = Cl - , Br - , and I - , in Acetonitrile Solution: Metal-Centered vs Ligand-to-Metal Charge-Transfer Assignments. Inorg. Chem. 1999, 38 (11), 2742-2745.

(42) Dkhil, S. Ben; Pfannmöller, M.; Saba, M. I.; Gaceur, M.; Heidari, H.; VidelotAckermann, C.; Margeat, O.; Guerrero, A.; Bisquert, J.; Garcia-Belmonte, G.; et al. Toward High-Temperature Stability of PTB7-Based Bulk Heterojunction Solar Cells: Impact of Fullerene Size and Solvent Additive. Adv. Energy Mater. 2017, 7 (4), 1-11.

(43) Ben Dkhil, S.; Pfannmöller, M.; Schröder, R. R.; Alkarsifi, R.; Gaceur, M.; Köntges, W.; Heidari, H.; Bals, S.; Margeat, O.; Ackermann, J.; et al. Interplay of Interfacial Layers and Blend Composition To Reduce Thermal Degradation of Polymer Solar Cells at High Temperature. ACS Appl. Mater. Interfaces 2018, 10 (4), 3874-3884.

(44) Rafique, S.; Abdullah, S. M.; Sulaiman, K.; Iwamoto, M. Fundamentals of Bulk Heterojunction Organic Solar Cells: An Overview of Stability/Degradation Issues and Strategies for Improvement. Renew. Sustain. Energy Rev. 2018, 84, 43-53.

(45) Perthué, A.; Gorisse, T.; Silva, H. S.; Lombard, C.; Bégué, D.; Hudhomme, P.; PépinDonat, B.; Rivaton, A.; Wantz, G. New Insights into Polymer Solar Cells Stability: The Crucial Role of PCBM Oxidation. J. Mater. Res. 2018, 33 (13), 1868-1878.

(46) Lechêne, B.; Leroy, J.; Tosoni, O.; de Bettignies, R.; Perrier, G. Origin of the S-Shape upon Aging in Standard Organic Solar Cells with Zinc Oxide as Transport Layer. $J$. Phys. Chem. C 2014, 118 (35), 20132-20136.

(47) Lim, F. J.; Krishnamoorthy, A.; Ho, G. W. Device Stability and Light-Soaking Characteristics of High-Efficiency Benzodithiophene-Thienothiophene CopolymerBased Inverted Organic Solar Cells with F-TiO x Electron-Transport Layer. ACS Appl. Mater. Interfaces 2015, 7 (22), 12119-12127. 


\section{TABLE OF CONTENTS}

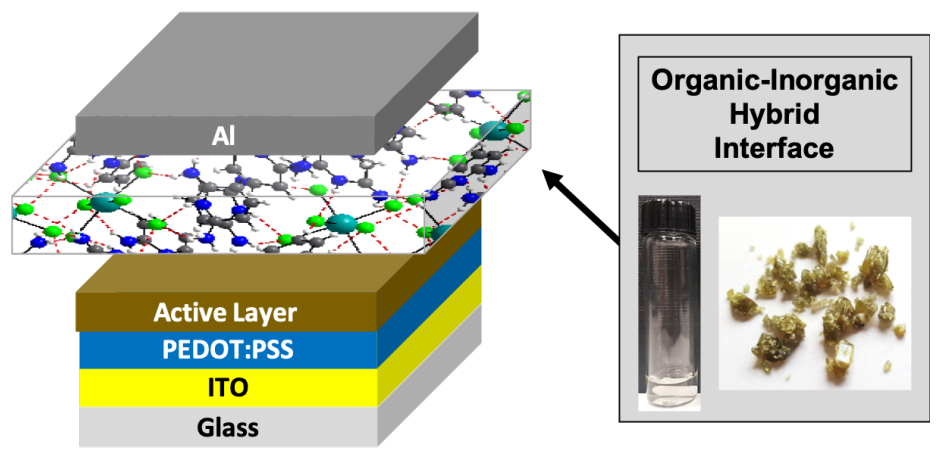

